\title{
Dopamine Imaging in Living Cells and Retina by Surface Enhanced Raman Scattering Based on Functionalized Gold Nanoparticles
}

Xueqian Ren ${ }^{\dagger} \ddagger, \perp$, Qingwen Zhang ${ }^{\dagger} \ddagger, \perp$, Jinglei Yang ${ }^{\dagger}, \perp$, Xinjuan Zhang ${ }^{\ddagger}$, Xueming

Zhang ${ }^{\ddagger}$, Yating Zhang ${ }^{\S}$, Liping Huang ${ }^{\dagger}, \dot{\ddagger}$, Changshun $\mathrm{Xu}^{\dagger, \ddagger}$, Yuancai Ge ${ }^{\dagger}$, , Hao Chen

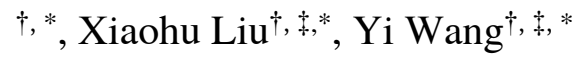

${ }^{\dagger}$ School of Biomedical Engineering, School of Ophthalmology \& Optometry, Wenzhou Medical University. Xueyuan Road 270, Wenzhou 325027, China.

${ }^{\ddagger}$ Wenzhou Institute, University of Chinese Academy of Sciences. Jinlian Road 1, Wenzhou 325001, China.

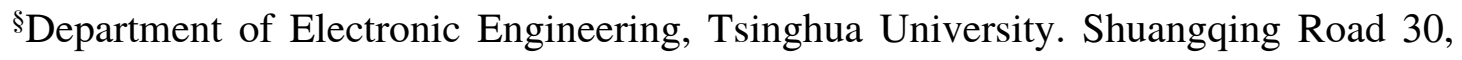
Beijing 100084, China.

*Email: wangyi@wiucas.ac.cn; liuxiaohu@wmu.edu.cn; chenhao@mail.eye.ac.cn

\section{Table of Contents}

1. Supplementary materials and methods. (Page S-2 to 7)

2. Characterizations of functional nanoprobes and controls including DLS, UV-vis and SERS sensitivity and selectivity analysis. (Page S-8 to 10)

3. Cellular analysis including cell viability tests, dopamine SERS images for controls and in large scale, and statistical table. (Page S-11 to 14)

4. Retinal analysis including dopamine SERS images in animal models, refraction and ocular axial length measurement of mice, HPLC measurements, and statistical figures and tables. (Page S-15 to 20) 
5. References. (Page S-21 to 22) 


\section{Supplementary materials and methods}

Dopamine hydrochloride, 3-sulfanylpropanenitrile (SPN), 3,3'-dithiodipropionic acid di (N-hydroxysuccinimide ester) (DSP), 4-Bromobutylboronic acid, lactate (Lac), adenosine (AD) were purchased from Sigma-Aldrich. Mercaptoethylamine (MP), Gold (III) chloride trihydrate $\left(\mathrm{HAuCl}_{4} \cdot 3 \mathrm{H}_{2} \mathrm{O}\right)$, trisodium citrate dihydrate, glucose (Glu), ascorbic acid (AA), Epinephrine hydrochloride (E), uric acid (UA), $\mathrm{NaOH}$, tyrosine (Tyr) and phenylalanine (Phe) were purchased from Macklin (Shanghai, China). 5hydroxyindole-3-acetic acid (5-HIAA) was purchased from Aladdin (Shanghai, China). Ghrelin (rat), Endogenous GHS agonist was purchased from Abcam (Shanghai, China). Tyrode's Salts Solution and Penicillin-Streptomycin Solution were purchased from Phygeng (Fujian, China). $\mathrm{AgNO}_{3}$ was purchased from Sinopharm Chemical Reagent Co., Ltd. Cell Counting Kit-8 (CCK-8) reagent was purchased from Dojindo (Shanghai, China). All the reagents were used as received without further purification. Ultrapure water $(\geq 18 \mathrm{M} \Omega \mathrm{cm})$ purified with a ULUPURE ultrapure water equipment was used throughout the work. PC12 cells was purchased from Procell Life Science \& Technology Co., Ltd. All animal studies were conducted in accordance with the Association for Research in Vision and Ophthalmology Statement for Use of Animals in Ophthalmic and Vision Research and approved by the Animal Care and Ethics Committee at Wenzhou Medical University, Wenzhou, China. C57BL/6 mice were obtained from Nanjing BioMedical Research Institute of Nanjing University. Guinea pigs (Cavia porcellus, the English short hair stock, tricolor strain) were obtained from the animal laboratory center of Zhejiang University in Hangzhou, China. All mice were 
housed in temperature-controlled rooms with a 12/12-h light/dark cycle. The animals had free access to standard food and water.

UV-vis absorption spectra were measured using a PerkinElmer UV-visible spectrometer with a standard $10-\mathrm{mm}$ path length quartz cuvette. The Raman spectra and cell imaging were collected on Renishaw Confocal Raman System. Synergy NEO2 Microplate Reader (Bio-Tek Instruments, Inc.) was used to record the absorbance of orange-yellow formazan in 96-well plates. TEM images were collected using the Talos F200S model from Thermo Fisher. Photo acquisition were performed using the Xiaomi 6x phone. The size of gold nanoparticles was measured by Zetasizer Nano ZS ZEN3600 from Malvern, UK. Axial length of guinea pig was measured by A-scan ultrasonography (AVISO Echograph Class I-Type Bat; Quantel Medical, ClermontFerrand, France). High-performance liquid chromatography detection of dopamine by Thermo Scientific with detection analyzer (Thermo UniMate 3000 Pump) and electrochemical detector (ESA Coulochem III Electrochemical Detector).

\section{Synthesis of AuNPs and BME}

AuNPs were synthesized according to silver (I)-assisted citrate reduction as reported previously. ${ }^{1}$ All glassware were soaked in fresh aqua regia $\left(\mathrm{HNO}_{3} / \mathrm{HCl}, 1: 3, \mathrm{v} / \mathrm{v}\right)$ for 2 h, and then rinsed with deionized water for later use. Briefly, $85 \mu \mathrm{L}$ of $\mathrm{AgNO}_{3}$ aqueous solution $(0.1 \%$ by weight $)$ and $600 \mu \mathrm{L}$ of citrate aqueous solution ( $1 \%$ by weight $)$ were added to $2 \mathrm{~mL}$ of $\mathrm{HAuCl}_{4}$ aqueous solution $(0.5 \%$ by weight). The total volume of the solution is $5 \mathrm{~mL}$ by adding deionized water, which was incubated at room temperature for $5 \mathrm{~min}$. The mixed solution was added to $95 \mathrm{~mL}$ of boiling water under vigorously 
stirred in a $250 \mathrm{~mL}$ three-necked flask, and the color of the reaction solution will change from light yellow to gray blue then gradually to ruby red. The reaction was remained for $1 \mathrm{~h}$ to form Monodisperse Quasi-Spherical Gold Nanoparticles and then cooled to room temperature. The synthesized AuNPs were stored in a refrigerator at $4{ }^{\circ} \mathrm{C}$ for further usage. For the synthesis of BME, mercaptoethylamine in ethanol solution (2 $\mathrm{mM}$ ) was added into $2 \mathrm{mM}$ of 4-bromobutylboronic acid at $80{ }^{\circ} \mathrm{C}$ under strong stirring. The solution was kept boiling for $2 \mathrm{~h}$ followed by cooling to room temperature. The reaction solution was stored at $4{ }^{\circ} \mathrm{C}$ until usage.

\section{Detection of dopamine}

The mixed solution was photographed by smart phone and measured by UV-vis spectrometry. $20 \mu \mathrm{L}$ of the mixed solution was added on a silicon wafer for Raman measurement under the condition of $17 \mathrm{~mW}$ He-Ne laser $(632.8 \mathrm{~nm})$, a L50× objective lens and integration time of $10 \mathrm{~s}$.

\section{Cytotoxicity test}

The PC12 cells were cultured in DMEM medium supplemented by $10 \%$ FBS and penicillin/streptomycin (1\%) under a humidified atmosphere. CCK-8 assay was used to detect cell viability based on intracellular dehydrogenase. The main component WST ${ }^{\circledR}$ 8 in CCK-8 was reduced to water-soluble orange-yellow formazan by dehydrogenase in living cells, and the amount of orange-yellow formazan was proportional to the number of living cells. The cells were seeded in 96-well plate at a concentration of $5 \times 10^{4}$ cells $/ \mathrm{mL}$, and cultured for $24 \mathrm{~h}$ at atmosphere of $5 \% \mathrm{CO}_{2}$ at $37^{\circ} \mathrm{C}$. Functionalized AuNPs probes $(0,0.04 \mathrm{nM}, 0.07 \mathrm{nM}$ and $0.1 \mathrm{nM})$ were added to the fresh culture 
medium and incubated with the cells for $24 \mathrm{~h}$. The cells were then incubated with 100 $\mu \mathrm{L}$ fresh medium and $10 \mu \mathrm{L}$ CCK-8 reagent for $3 \mathrm{~h}$. The absorbance of the cells was measured at $450 \mathrm{~nm}$ with a microplate reader.

\section{Establishment of form deprivation myopia}

Refraction and axial length of male mice and guinea pig was measured as reported previously. ${ }^{2-5}$ Refraction of male mice and guinea pig were measured using an eccentric infrared photorefractor designed by Schaeffel. Refraction of male mice at 6-week-old were recorded at baseline and measured at the vertical pupil meridian in darkness. Briefly, each mouse was placed on a platform that was slowly adjusted until a clear first Purkinje image occurred in the center of the pupil, indicating an on-axis measurement. The data were then automatically recorded by the program and reported as the mean of at least three measurements. Refraction of guinea pig at 6-week-old was measured at the vertical meridian without cycloplegia. The three data were automatically recorded and reported. Mice and guinea pig with inter-eye difference in refraction less than 3 diopters were randomly divided into 2 groups, FD group and normal control group. In guinea pigs without anesthesia, axial length (the distance from the cornea to the retina) were measured by A-scan ultrasonography. Axial length of male mice was measured by real-time optical coherence tomography (a custom-made OCT). During the measurement, the position of custom-made OCT should be aligned with the optical axis of the eye. For mice in FD group, FD was produced by gluing a translucent lens to cover the right eye of the animals for 3-day or 2-week in the relevant groups. ${ }^{2,6}$ For guinea pig in FD group, FD was produced by a facemask to cover the right eye of the animals 
for 2-week in the relevant groups. ${ }^{7}$ No treatment was given to mice and guinea pig in normal control group.

\section{TEM measurement of guinea pig and mouse retina}

After anesthetized with ether, the guinea pig and mouse were killed by cervical spine dislocation. Removed the blindfold, and then the eyeballs of mouse were immediately dug out and placed in the fixative (paraformaldehyde: glutaraldehyde: $0.2 \mathrm{M}$ phosphate buffer=1:1:2). Eye surgery scissors was used to cut the muscles on the eyeball, and then cut along upper edge of the corneoscleral limbus to remove the cornea, iris, and lens. After cut along the optic papilla, a scalpel was used to trim a piece into a rectangle, then cut it into the thinnest possible rectangular strip, and putting small retina tissue in the fixative for use. TEM measurement of guinea pig and mouse retina as reported previously. ${ }^{8}$ The small retinal tissues were washed with $\mathrm{pH}=7.2$ phosphate buffer $(0.1$ $\mathrm{M}$ ), soaked in $4 \%$ osmium tetroxide for $1 \mathrm{~h}$, and then washed with deionized water. They were treated with $0.5 \%$ uranyl acetate for $1 \mathrm{~h}$, and then treated with different concentrations of alcohol $(3 \%, 5 \%, 7 \%, 9 \%, 95 \%, 100 \%)$ for dehydration. After embedded with epoxy resin, they were cut into $70 \mathrm{~nm}$ slices with an ultra-thin microtome (Leica EM UC7). They were stained with 5\% uranyl acetate in citric acid solution for TEM imaging.

\section{HPLC detection of dopamine in guinea pig and mouse retina}

HPLC of dopamine in guinea pig and mouse retina as reported previously. ${ }^{9}$ Briefly, guinea pig and mouse were sacrificed after FD treatments. Guinea pig and mouse retinas were collected and placed in a cryotube containing $100 \mu \mathrm{L} 0.1 \mathrm{M}$ perchloric acid 
(containing $10 \mu \mathrm{M}$ ascorbic acid, $0.1 \mathrm{mM}$ ethylenediaminetetraacetic acid (EDTA) disodium salt, $0.02 \mu \mathrm{M}$ 3,4-dihydroxybenzyl-amine) and recorded the weight. Subsequently, the collected retina was homogenized by ultrasound on ice, which centrifuged at $14000 \mathrm{rpm}$ at $4{ }^{\circ} \mathrm{C}$ for $10 \mathrm{~min}$. The supernatant was taken stored at -80 ${ }^{\circ} \mathrm{C}$ until usage. The analytical column was $\mathrm{C} 18$ column (DIONEX Acclaim), and the column temperature maintained at $38{ }^{\circ} \mathrm{C}$. HPLC analysis employed mobile phase containing $\mathrm{NaH}_{2} \mathrm{PO}_{4} 90 \mathrm{mM}$, citric acid $50 \mathrm{mM}$, EDTA $0.05 \mathrm{mM}$, ortho silicic acid 1.7 $\mathrm{mM}$, and acetonitrile $5 \%$, and a flow rate of $0.2 \mathrm{ml} / \mathrm{min}$. The injection volume is $10 \mu \mathrm{L}$. Chromeleon chromatography workstation was used for data collection and analysis. 

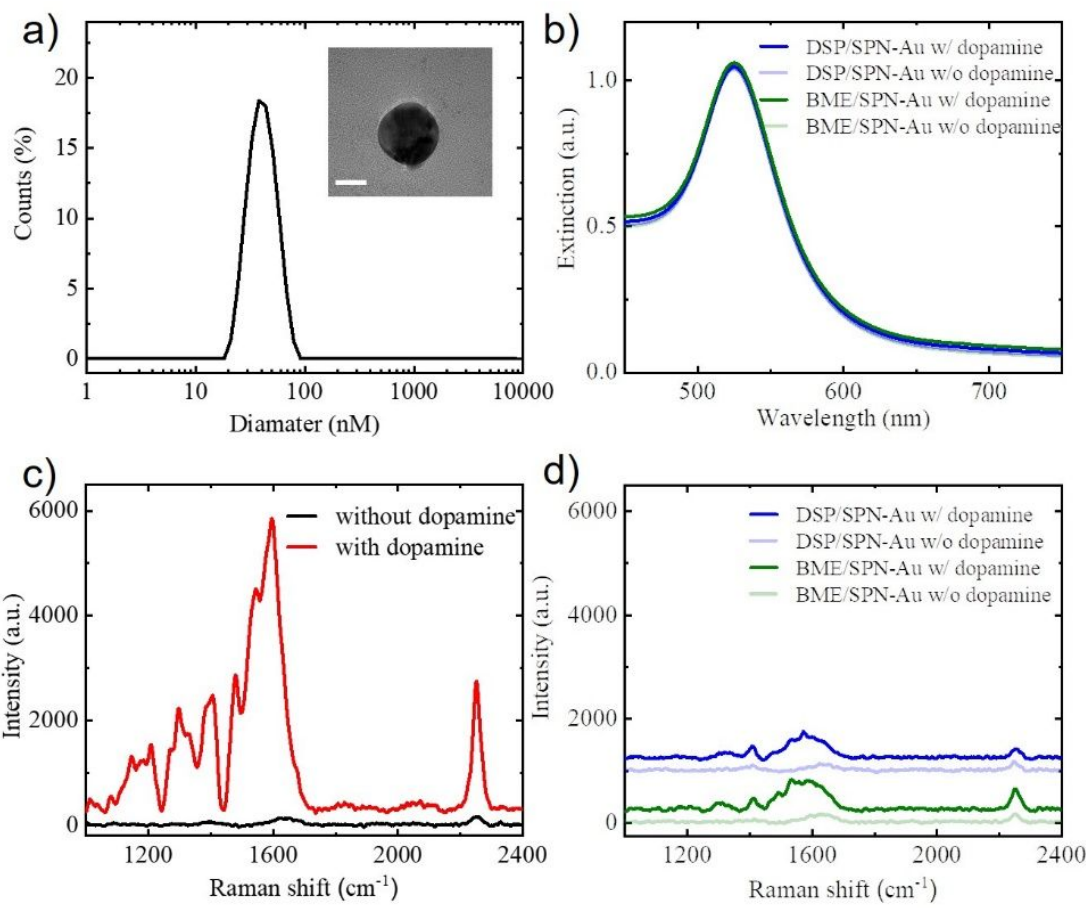

Figure S1. a) DLS data of synthesized AuNPs showing the average size at around 40 nm. Inset: TEM image of a single gold nanoparticle. Scale bar: $20 \mathrm{~nm}$. b) UV-vis spectra after addition of $5 \mu \mathrm{M}$ dopamine by using both the DSP/SPN-Au (blue) and BME/SPN$\mathrm{Au}$ (green) as controls, respectively. Lighter colors indicate absence of dopamine. c) SERS spectra of the BME/DSP/SPN-Au before (black) and after (red) addition of dopamine. d) SERS spectra after addition of $5 \mu \mathrm{M}$ dopamine by using both the DSP/SPN-Au (blue) and BME/SPN-Au (green) as controls, respectively. Lighter colors indicate absence of dopamine. 

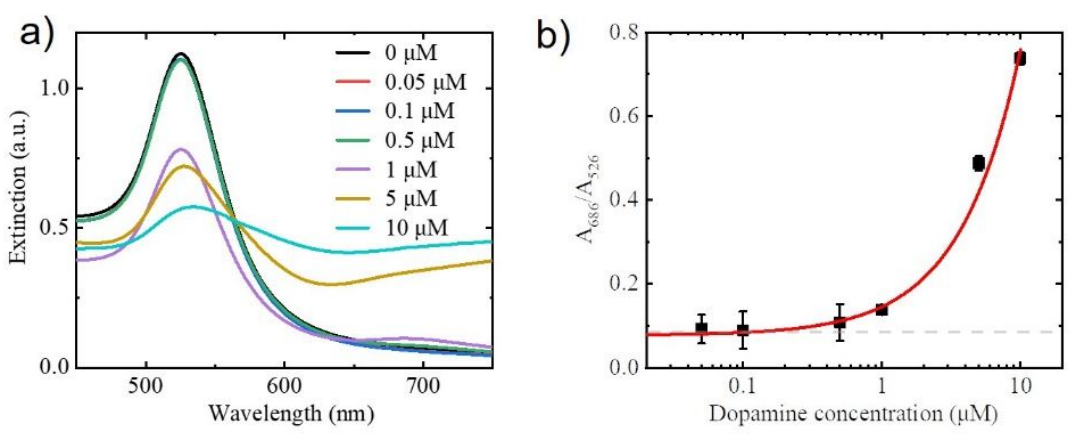

Figure S2. a) UV-vis spectra of the BME/DSP/SPN-Au nanoprobes 30 min after the addition of different concentrations of dopamine: $0 \mu \mathrm{M}, 0.05 \mu \mathrm{M}, 0.1 \mu \mathrm{M}, 0.5 \mu \mathrm{M}, 1$ $\mu \mathrm{M}, 5 \mu \mathrm{M}$, and $10 \mu \mathrm{M}$. b) Plot of intensity ratios as A686/A526 versus different concentrations of dopamine. Broken grey line represented three times of standard deviation of blank samples for LOD estimation. Error bars showed the standard deviation of at least three independent measurements. 
a)

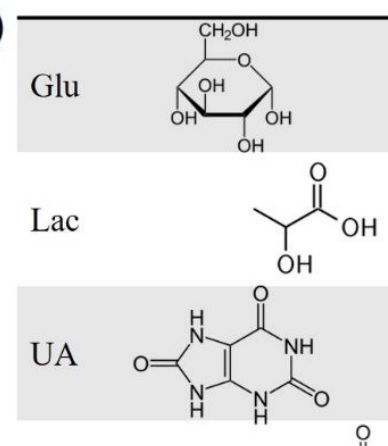<smiles>N[C@@H](Cc1ccccc1)C(=O)O</smiles><smiles>NC(Cc1ccc(O)cc1)C(=O)O</smiles>

$\mathrm{AD}$
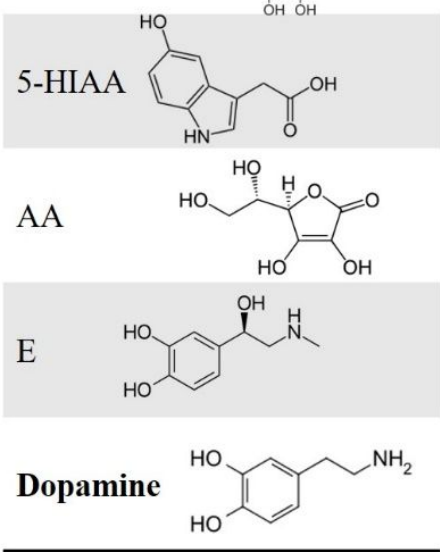
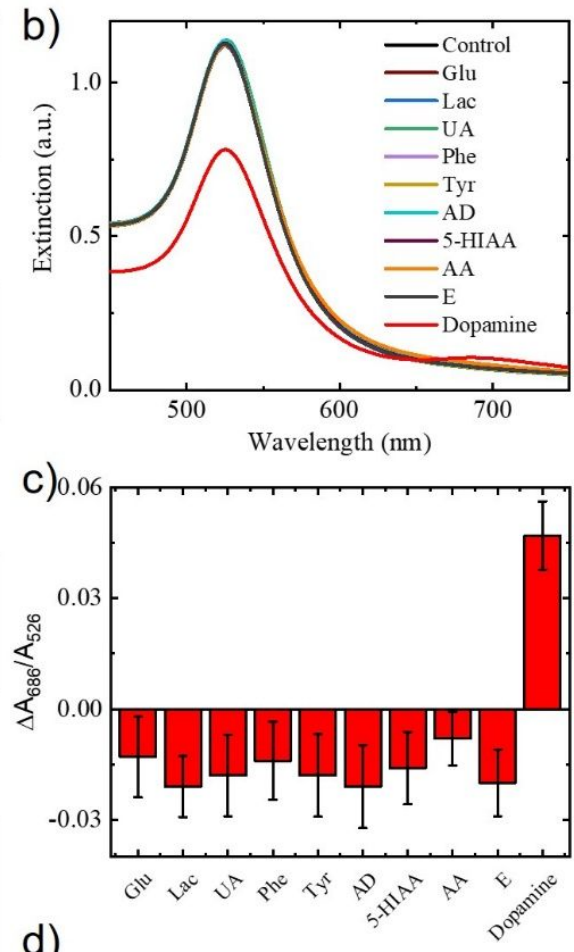

d)

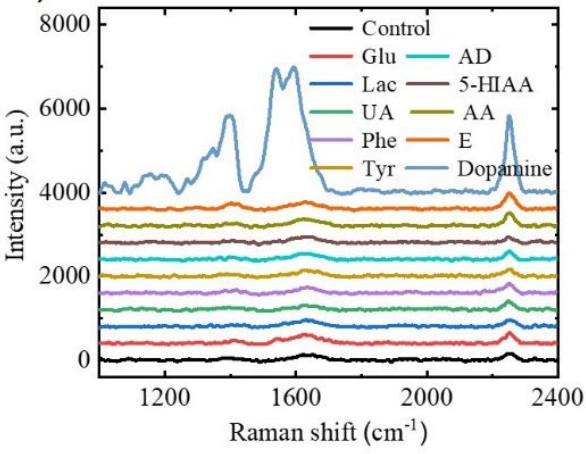

Figure S3. a) The molecular structures of glucose (Glu), lactate (Lac), uric acid (UA), phenylalanine (Phe), tyrosine (Tyr), adenosine (AD), 5-hydroxyindole-3-acetic acid (5HIAA), ascorbic acid (AA), epinephrine (E), and dopamine used for selectivity tests. b) UV-vis spectra of the BME/DSP/SPN-Au nanoprobes 30 min after the addition of different molecules as in a) at $1 \mu \mathrm{M}$. c) Histogram of intensity ratios as A686/A526 derived from b). Error bars showed the standard deviation of at least three independent measurements. d) SERS spectra of the nanoprobes upon addition of different molecules as in a) at $1 \mu \mathrm{M}$. 
a)

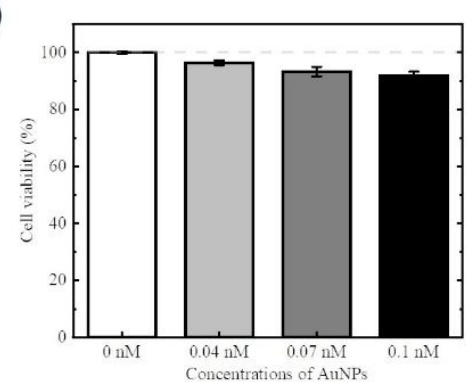

b)

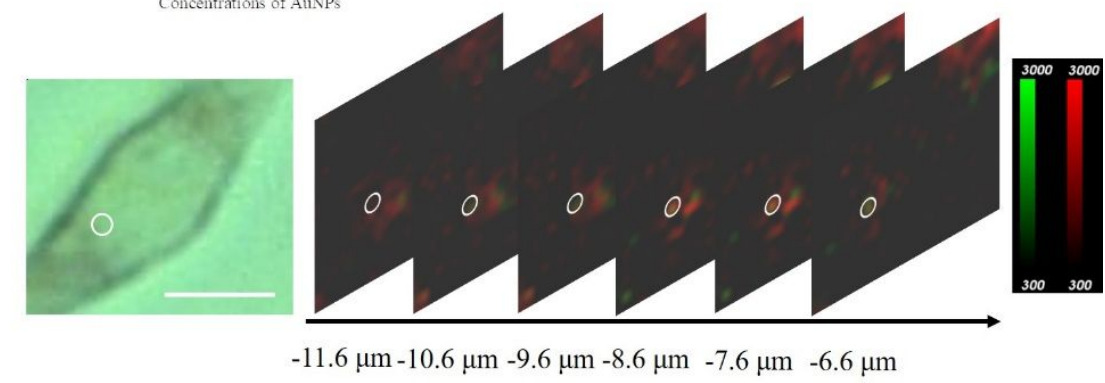

c)

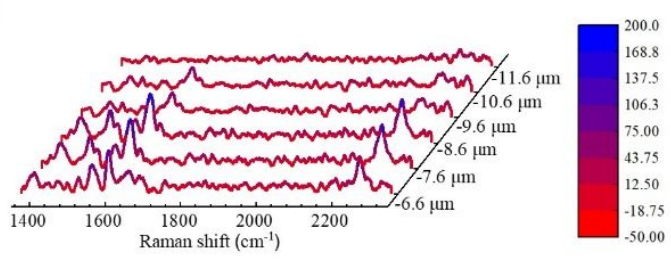

Figure S4. Cell viability test and 3D imaging of dopamine in single PC12 cell. a) Histogram of cell viability tests by using CCK-8 assay for different concentrations of AuNPs from 0 to $0.1 \mathrm{nM}$. The error bars represent the standard deviations of ten parallel samples. b) Bright-field image of a single PC12 cell and SERS mapping images obtained in different layers of the same cell in the $\mathrm{z}$ direction. Scale bar: $10 \mu \mathrm{m} . \mathrm{c})$ SERS spectra from different layers in white circles in b). 


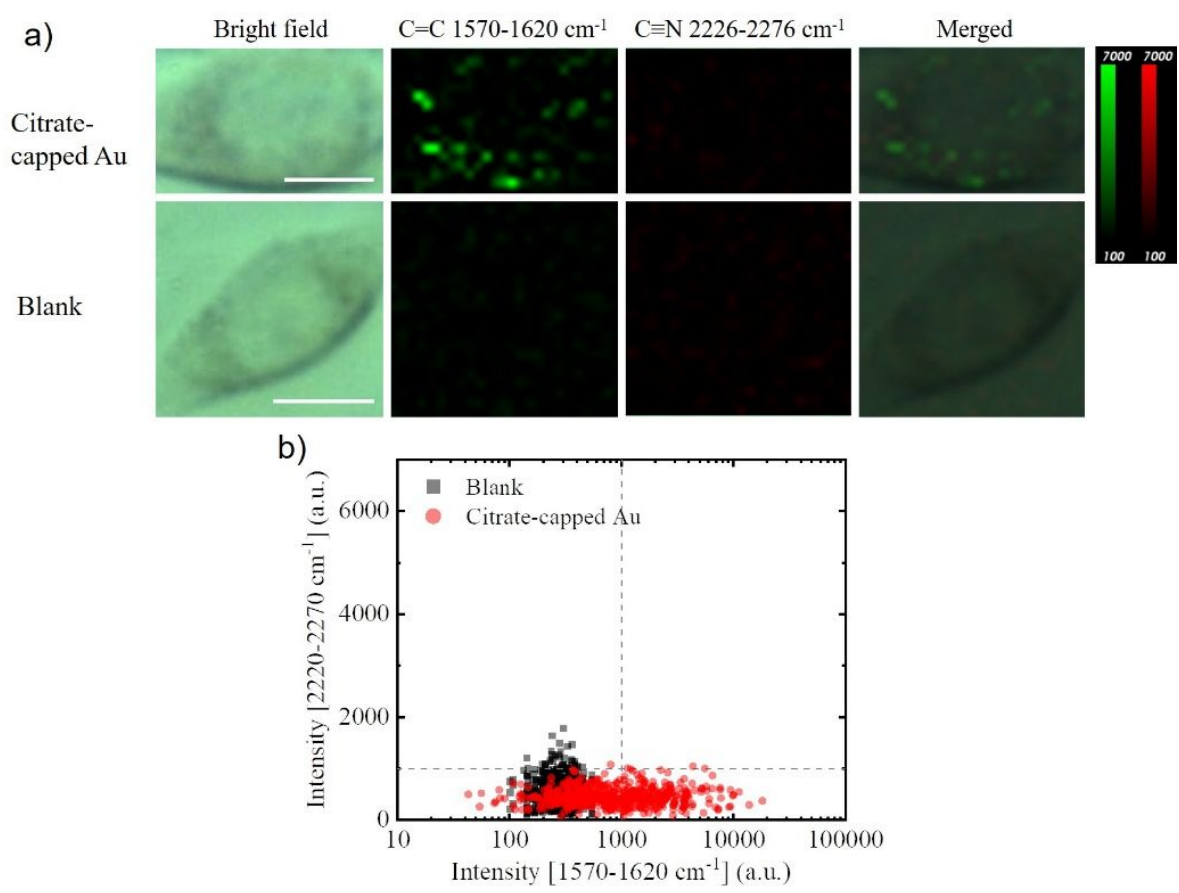

Figure S5. SERS imaging of dopamine in single PC12 cells incubated with and without citrate-capped AuNPs as controls. a) Bright-field, SERS mapping images of single living cells acquired in $1570-1620 \mathrm{~cm}^{-1}$ and $2226-2276 \mathrm{~cm}^{-1}$ channels and their merged images. Top: PC12 cells incubated with citrate-capped AuNPs. Bottom: PC12 cells only. Scale bar: $10 \mu \mathrm{m}$. b) Scatter plot of pixel intensities in Raman images of PC12 cells incubated with citrate-capped AuNPs (red circles) and PC12 cells only (black squares), where the $\mathrm{x}$-axis indicating the intensity integral derived from $1570-1620 \mathrm{~cm}^{-1}$ channel and the y-axis indicating the intensity integral derived from $2226-2276 \mathrm{~cm}^{-1}$ channel. 


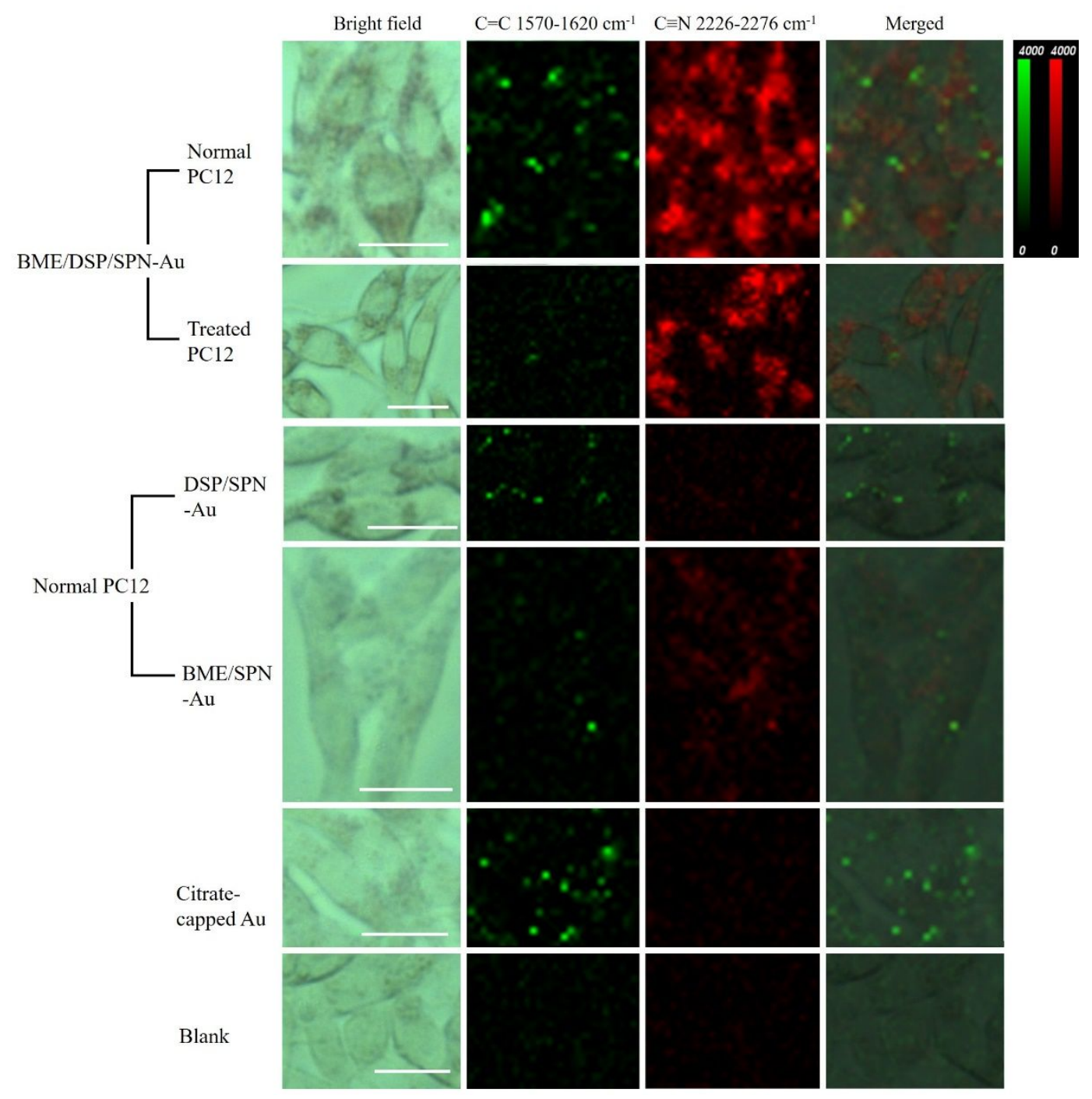

Figure S6. SERS imaging of dopamine in multiple PC12 cells under various conditions.

Bright-field, SERS mapping images of multiple living cells acquired in $1570-1620 \mathrm{~cm}^{-1}$ and 2226-2276 $\mathrm{cm}^{-1}$ channels and their merged images. From top to bottom: PC12 cells incubated with BME/DSP/SPN-Au; ghrelin-pretreated PC12 cells incubated with BME/DSP/SPN-Au; PC12 cells incubated with DSP/SPN-Au, BME/SPN-Au and citrate-capped AuNPs; and PC12 cells only. Scale bar: $20 \mu \mathrm{m}$. 
Table S1. Percentages of each quadrant in Figure 3d and 3e for all PC12 groups. The threshold value was set at 1000 a.u. for both $1570-1620 \mathrm{~cm}^{-1}$ and $2226-2276 \mathrm{~cm}^{-1}$ channels.

\begin{tabular}{|c|c|c|c|c|c|c|c|}
\hline $\mathbf{C}=\mathbf{C}$ & $\mathbf{C} \equiv \mathbf{N}$ & $\begin{array}{c}\text { BME/DSP } \\
(n=610)\end{array}$ & $\begin{array}{c}\text { Treated } \\
(n=611)\end{array}$ & $\begin{array}{c}\text { DSP } \\
(n=591)\end{array}$ & $\begin{array}{c}\text { BME } \\
(n=597)\end{array}$ & $\begin{array}{c}\text { Citrate } \\
(n=547)\end{array}$ & $\begin{array}{c}\text { Blank } \\
(n=534)\end{array}$ \\
\hline+ & + & $23.8 \%$ & $15.5 \%$ & $6.3 \%$ & $6.0 \%$ & $0.2 \%$ & 0 \\
\hline+ & - & $4.8 \%$ & $9.2 \%$ & $43.5 \%$ & $2.5 \%$ & $40.8 \%$ & 0 \\
\hline- & + & $67.9 \%$ & $62.2 \%$ & $4.4 \%$ & $82.4 \%$ & $0.2 \%$ & $5.4 \%$ \\
\hline- & - & $3.6 \%$ & $13.1 \%$ & $45.9 \%$ & $9.0 \%$ & $58.7 \%$ & $94.6 \%$ \\
\hline
\end{tabular}

+ : pixel intensity larger than threshold value 1000 .

-: pixel intensity smaller than threshold value 1000 . 
a) Normal retina Myopia
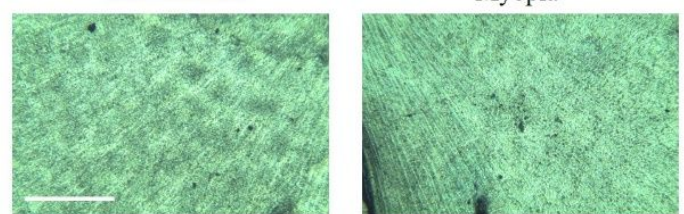

b)
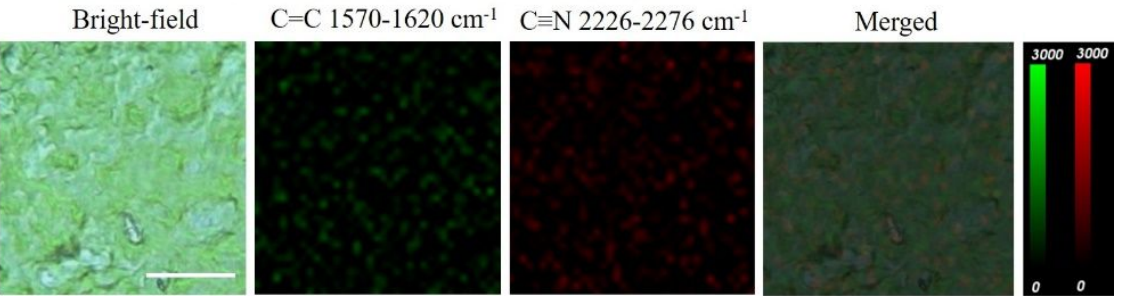

Figure S7. SERS imaging of dopamine in guinea pig retina. a) Bright-field images of normal retina and retina from myopia model. Scale bar: $200 \mu \mathrm{m}$. b) Bright-field, SERS mapping images of guinea pig retinal tissues without nanoprobes acquired in 1570$1620 \mathrm{~cm}^{-1}$ and 2226-2276 $\mathrm{cm}^{-1}$ channels and their merged images. Scale bar: $20 \mu \mathrm{m}$. 

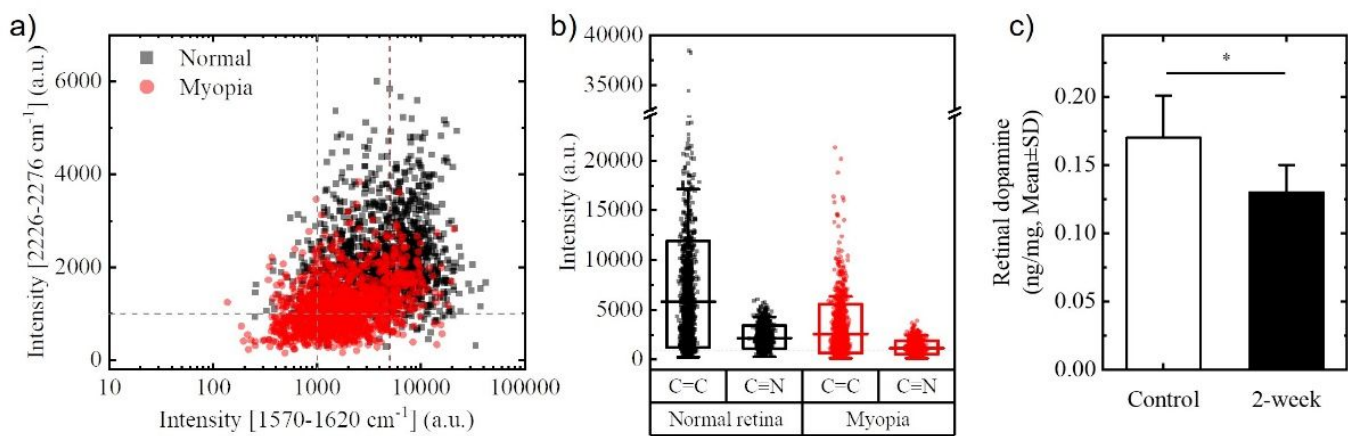

Figure S8. a) Scatter plot of pixel intensities in Raman images of normal retinal tissue (black squares) and retina from myopia model (red dots) of guinea pigs. b) The boxplot of pixel intensities in Raman images of normal retinal tissue (black squares) and retina from myopia model (red dots). Within each group the left and right boxes showed the averaged intensities in $1570-1620 \mathrm{~cm}^{-1}(\mathrm{C}=\mathrm{C})$ and $2226-2276 \mathrm{~cm}^{-1}(\mathrm{C} \equiv \mathrm{N})$ channels, respectively. c) HPLC analysis of total dopamine amount in normal retina (white, control) and retina from myopia model (black, FD) $(\mathrm{n}=4)$. 
Table S2. Percentages of each quadrant in Figure S8a for both guinea pig retina groups.

The threshold value was set at 1000 or 5000 a.u. for $1570-1620 \mathrm{~cm}^{-1}$ channel and at 1000 a.u. for $2226-2276 \mathrm{~cm}^{-1}$ channel.

\begin{tabular}{cc|cc}
\hline $\mathbf{C}=\mathbf{C}$ & $\mathbf{C} \equiv \mathbf{N}$ & $\begin{array}{c}\text { Normal } \\
(\mathbf{n}=\mathbf{1 2 3 0})\end{array}$ & $\begin{array}{c}\text { Myopia } \\
(\mathbf{n}=\mathbf{1 1 8 1})\end{array}$ \\
\hline+ & + & $\mathbf{8 7 . 0 \%}$ & $\mathbf{4 5 . 5 \%}$ \\
\hline+ & - & $6.0 \%$ & $32.3 \%$ \\
\hline- & + & $5.3 \%$ & $7.8 \%$ \\
\hline- & - & $1.7 \%$ & $14.4 \%$ \\
\hline$+^{*}$ & + & $\mathbf{4 2 . 9 \%}$ & $\mathbf{1 0 . 6 \%}$ \\
\hline
\end{tabular}

$+:$ pixel intensity larger than threshold value 1000 .

-: pixel intensity smaller than threshold value 1000 .

$+^{*}$ : pixel intensity larger than threshold value 5000 . 

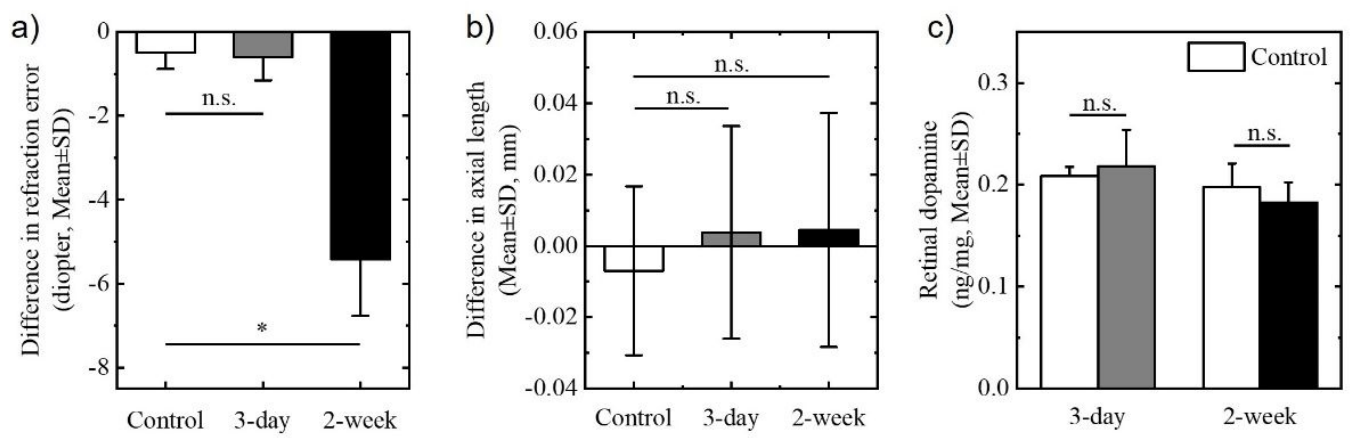

Figure S9. a) Optical measurements of refraction in mice treated with 3-day and 2-week FD, and untreated controls ( $n=4$ for each group). b) Measurements of ocular axial length in 3-day and 2-week form deprivation treated mice, compared to control $(n=6)$. c) HPLC analysis of total dopamine amount in retina from 3-day FD model (grey) and 2-week FD model (black), compared to their controls from normal retina (white) (3day FD, $\mathrm{n}=4$; 2-week FD, $\mathrm{n}=6$ ). 
a)
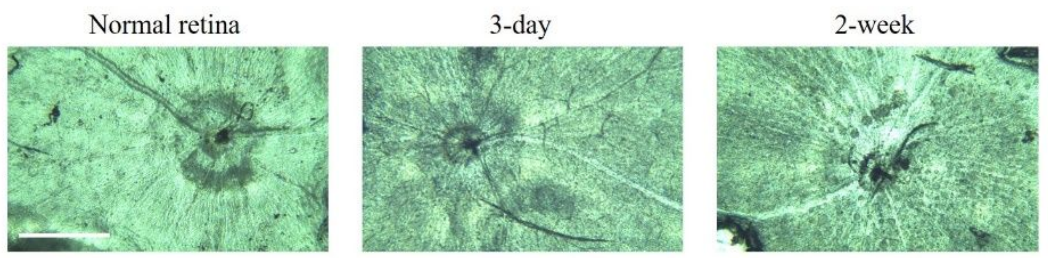

b)
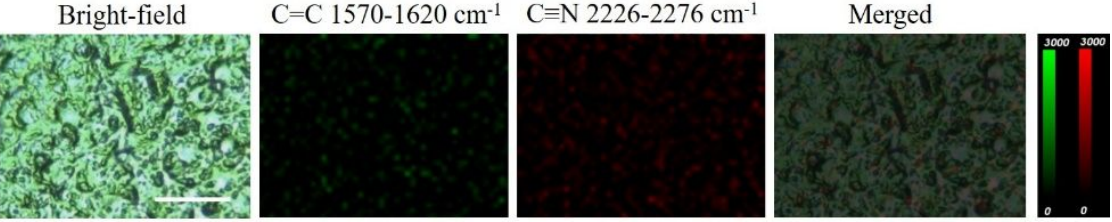

Figure S10. SERS imaging of dopamine in mice retina. a) Bright-field images of normal retina and retina from 3-day and 2-week form deprivation treated mice. Scale bar: 200 $\mu \mathrm{m} . \mathrm{b})$ Bright-field, SERS mapping images of mice retinal tissues without nanoprobes acquired in $1570-1620 \mathrm{~cm}^{-1}$ and $2226-2276 \mathrm{~cm}^{-1}$ channels and their merged images. Scale bar: $20 \mu \mathrm{m}$. 
Table S3. Percentages of each quadrant in Figure $4 \mathrm{~h}$ for all mice retina groups. The threshold value was set at 1000 or 5000 a.u. for $1570-1620 \mathrm{~cm}^{-1}$ channel and at 1000 a.u. for $2226-2276 \mathrm{~cm}^{-1}$ channel.

\begin{tabular}{cc|ccc}
\hline $\mathbf{C}=\mathbf{C}$ & $\mathbf{C} \equiv \mathbf{N}$ & $\begin{array}{c}\text { Normal } \\
(\mathbf{n}=\mathbf{1 0 4 9})\end{array}$ & $\begin{array}{c}\text { 3-day } \\
(\mathbf{n}=\mathbf{1 0 1 6})\end{array}$ & $\begin{array}{c}\text { 2-week } \\
(\mathbf{n}=\mathbf{1 0 3 5})\end{array}$ \\
\hline+ & + & $\mathbf{7 9 . 0 \%}$ & $\mathbf{7 0 . 2 \%}$ & $\mathbf{2 5 . 2 \%}$ \\
+ & - & $16.3 \%$ & $9.7 \%$ & $18.0 \%$ \\
\hline- & + & $4.3 \%$ & $15.8 \%$ & $24.7 \%$ \\
\hline- & - & $0.4 \%$ & $4.2 \%$ & $32.1 \%$ \\
\hline${ }^{*}$ & + & $\mathbf{6 2 . 4 \%}$ & $\mathbf{4 2 . 3 \%}$ & $\mathbf{4 . 3 \%}$ \\
\hline
\end{tabular}

+ : pixel intensity larger than threshold value 1000 .

-: pixel intensity smaller than threshold value 1000 .

$+^{*}$ : pixel intensity larger than threshold value 5000 . 


\section{References}

1. Xia, H. B.; Bai, S. O.; Hartmann, J.; Wang, D. Y., Synthesis of Monodisperse Quasi-Spherical Gold Nanoparticles in Water via Silver(I)-Assisted Citrate Reduction. Langmuir 2010, 26 (5), 3585-3589.

2. Schaeffel, F.; Burkhardt, E.; Howland, H. C.; Williams, R. W., Measurement of Refractive State and Deprivation Myopia in Two Strains of Mice. Optom. Vis. Sci. 2004, $81(2), 99-110$.

3. Schippert, R.; Burkhardt, E.; Feldkaemper, M.; Schaeffel, F., Relative Axial Myopia in Egr-1 (ZENK) Knockout Mice. Invest. Ophthalmol. Vis. Sci. 2007, 48 (1), $11-17$

4. Zhou, X. T.; Xie, J.; Shen, M. X.; Wang, J. H.; Jiang, L. Q.; Qu, J.; Lu, F., Biometric Measurement of the Mouse Eye Using Optical Coherence Tomography with Focal Plane Advancement. Vision Res. 2008, 48 (9), 1137-1143.

5. Ng, V.; Kroetz, D. L., Cytochrome P450 Eicosanoids Regulate Fatty Acid Metabolism via PPAR Alpha. Clin. Pharmacol. Ther. 2004, 75 (2), P45-P45.

6. Zhou, X. T.; Ji, F. T.; An, J. H.; Zhao, F. X.; Shi, F. J.; Huang, F. R.; Li, Y.; Jiao, S. M.; Yan, D. S.; Chen, X. Y.; Chen, J. F.; Qu, J., Experimental Murine Myopia Induces Collagen Type I Alpha 1 (COL1A1) DNA Methylation and Altered COL1A1 Messenger RNA Expression in Sclera. Mol. Vis. 2012, 18 (137-41), 1312-1324.

7. Lu, F.; Zhou, X. T.; Zhao, H. L.; Wang, R. Q.; Jia, D.; Jiang, L. Q.; Xie, R. Z.; Qu, J., Axial Myopia Induced by a Monocularly-Deprived Facemask in Guinea Pigs: A Non-Invasive and Effective Model. Exp. Eye Res. 2006, 82 (4), 628-636. 
8. Nativo, P.; Prior, I. A.; Brust, M., Uptake and Intracellular Fate of SurfaceModified Gold Nanoparticles. ACS Nano 2008, 2 (8), 1639-1644.

9. Wu, X.-H.; Li, Y.-Y.; Zhang, P.-P.; Qian, K.-W.; Ding, J.-H.; Hu, G.; Weng, S.-J.; Yang, X.-L.; Zhong, Y.-M., Unaltered Retinal Dopamine Levels in a C57BL/6 Mouse Model of Form-Deprivation Myopia. Invest. Ophthalmol. Vis. Sci. 2015, 56 (2), 967977. 